\title{
PROFESSIONAL ROLES OF A DANCE TEACHER AND THEIR ANALYSIS IN HIGHER EDUCATION
}

\author{
Paula Jegere \\ Latvian Association of Dance Teachers, Latvia
}

\begin{abstract}
Dance teachers fulfil different roles in their daily work. It reflects as a need to act according to the circumstances that appear as a part of work process. If the economic situation in a certain country is unstable then more professionals are urged to obtain additional knowledge to use skills necessary for the development and sustainability of the profession. Skills that are often provided by other specialists in a different field of work. First of all the roles that are fulfil in a daily work need to be acknowledged and supported -denial of these roles can influence professional work/activity. Then according to the financial status occurs roles of secondary meaning, not used in the daily professional activities but rather occasionally. The recognition of one's professional roles and their variability may take place in the higher education study process, when students realize and are motivated to obtain more information and knowledge/skills to expand their professional work. The aim of this article is to analyse professional roles of students in different higher education dance programs. The aim is carried out in the analysis of literature and on it's base promoted evaluation indicators and levels of professional roles realized by dance teachers. A questionnaire is designed on a basis of these indicators and levels and offered for approbation to students in higher education dance programs in Latvian Academy of Music, Liepaja University, Latvian Academy of Culture.
\end{abstract}

Keywords: professional roles, dance pedagogy.

\section{Introduction}

Professionals in the art of dance should know their profession and seek to understand and expand their knowledge in fields that are closely related to their profession but are not a part of their daily work activities.

O. Nikiforov (2007) states that the social role is a fixation of particular position occupied by one or another individual in the system of public relations. Specifically, a role is understood as a normatively approbated pattern of behaviour that is expected of anyone in this position. These roles cannot be perceived as absolute patterns of behaviour, as each individual discloses his or her own character in interaction with others (Nikiforovs, 2007).

Primary roles are related to everyday professional activities and include knowledge and skills acquired during the study process, which will complement during the professional work experience. Secondary roles, on the other hand, are 
used less frequently in everyday professional activities, but they reflect the broad interaction of dance with other forms of art, medicine and science.

In actual process of personality development it should be noted that every field of activity - cognitive or creative work, perception of artwork, sport's activities, etc. - always receive support from other areas (Anspaks, 2006).

Table 1 Professional roles of a dance teacher (by author)

\begin{tabular}{|c|c|}
\hline Primary roles & Secondary roles \\
\hline Teacher & $\begin{array}{r}\text { Physiotherapist / Injury Diagnosis } \\
\text { and Primary Care }\end{array}$ \\
\hline Educator & Seamstress / Costume, prop, designer \\
\hline Choreographer & Nutrition specialist \\
\hline Manager/ Event organizer & Scientist \\
\hline Adviser & Photographer, operator \\
\hline Music connoisseur & Director, scenographer \\
\hline Psychologist & \\
\hline
\end{tabular}

In the professional life of a dance teacher primary roles are based on daily work and are as inclusive as the individual's education. Of course, a dance teacher in the role of a psychologist will not be able to perform the duties of a professional psychologist. In this case, daily work requires knowledge of psychology to determine the consequences of action. For example, when working with students, it is necessary to understand people's psychotypes, character, problem solving and conflict resolution, and so on. When dealing with students of special needs, it is necessary to be aware of the issues in question. The dance teacher uses all the acquired knowledge in the field of psychology, thus applying the knowledge in the work process, the dance teacher takes the role of a psychologist.

\section{Literature review}

"Educator", "Choreographer" and "Manager" were selected as the most important roles in revealing the professional activities of a dance teacher.

First, the teacher is unquestionably also an educator, because, according to A. Spona (2006), upbringing is a complex, long-lasting, continuous human cooperation in which three important functions are realized: acquisition, preservation and development of the spiritual values of humanity.

The role of "choreographer" is undeniably important. Some dance teachers may not practice the profession in the course of his or her work, for example teaching only specific exercises or movement techniques. The exercises are designed for the better execution of choreography and mastering the movements of a particular dance genre, while the dance itself, with its musical accompaniment 
and dramaturgy, contributes to the artistic development of the personality. Therefore, even if the dance teacher himself does not create original dance pieces and teaches dance compositions created by other choreographers, he/she needs knowledge and skills in dance composition also to justify the choice of the selected repertoire. When it comes to contemporary dance styles, the role of the choreographer is undoubtedly one of the most important in the professional activities of a dance teacher. Given the interaction and synthesis of genres and styles in the modern dance world, a dance teacher needs an increasing knowledge of choreography to create an original dance composition that can gain recognition at competitions and festivals.

The head of the educational institution is responsible for the work of educational institution and its results, compliance with regulatory enactments, as well as rational use of intellectual, financial and material resources (Celma, 2006). A manager is a school employee with a great deal of responsibility who: knows what purpose he wants to achieve; controls resources; is an innovator; take's responsibility; creates motivation (Everard et al., 2004). The dance teacher can directly apply elements of management to the position of a dance studio leader, replacing the term "educational establishment" with "studio", "group" and so on applying the gained knowledge in a reduced structure of professional work.

It is possible that at the beginning of a dance teacher career he/she works as a professional in other studios, as a lecturer with students, etc., therefore not fulfilling the role of a manager. However if a dance teacher has a time when he/her realizes ideas and creative potential by creating a dance group, studio or a school, it leads to managing skills. There is also the opportunity to hire new dance teachers and continue to lead the studio and its creative team of teachers fulfilling the role in the end of the active career. It all represents a role of "manager" and in order to fulfil this role the teacher needs organizational skills. The dance teacher being also a "manager"- takes responsibility for his students and the artistic activities of the group/ studio/ school. Manager organizes concert activities, which includes communication with the organizers of the event, solving financial issues, selection of the appropriate artistic repertoire, provision of transport, etc.

In the literature a concept of an educational institution is fully in line with the development of a dance group/studio/school, as dance teachers eventually open accredited private dance schools, where management skills and knowledge are an integral part of successful professional practice. This includes knowledge of team management (pedagogical composition), educational institution management and operational functions, as well as many other knowledge and skills that a dance teacher can develop over time into a fully-fledged profession. 


\section{Methodology}

The aim is carried out in the analysis of literature and on its base created a model which promoted evaluation indicators and levels of professional roles of dance teachers. A questionnaire is designed on a basis of these indicators and levels. The respondents are 88 students in higher education dance programs in Latvian Academy of Music ("Choreographer", "Dance and Rhythmic teacher"), Latvian Academy of Culture ("Contemporary dance - Choreography") and Liepaja University (Dance and Sports teacher). 24 questionnaires were recognized to be invalid, relating to the fact that one study program integrated sports, therefore it could affect the results and the average point of view of "aspiring dance teacher".

The results showed that there are practically no common points that promote or reduce comprehension of professional roles. For example, it can't be said that first year students have lower activity or insight in professional roles than the students in the fourth year. Also the represented dance genre was not the determinant point to make a suggestion about lack of understanding. Neither the work experience nor age of students. According to the questionnaire 6 and 5 points represent total agreement to the offered statements, 4 and 3 represent neutral attitude, 2 and 1 represent total disagreement. The statements illustrate three main professional roles "educator”, “choreographer” and "manager”.

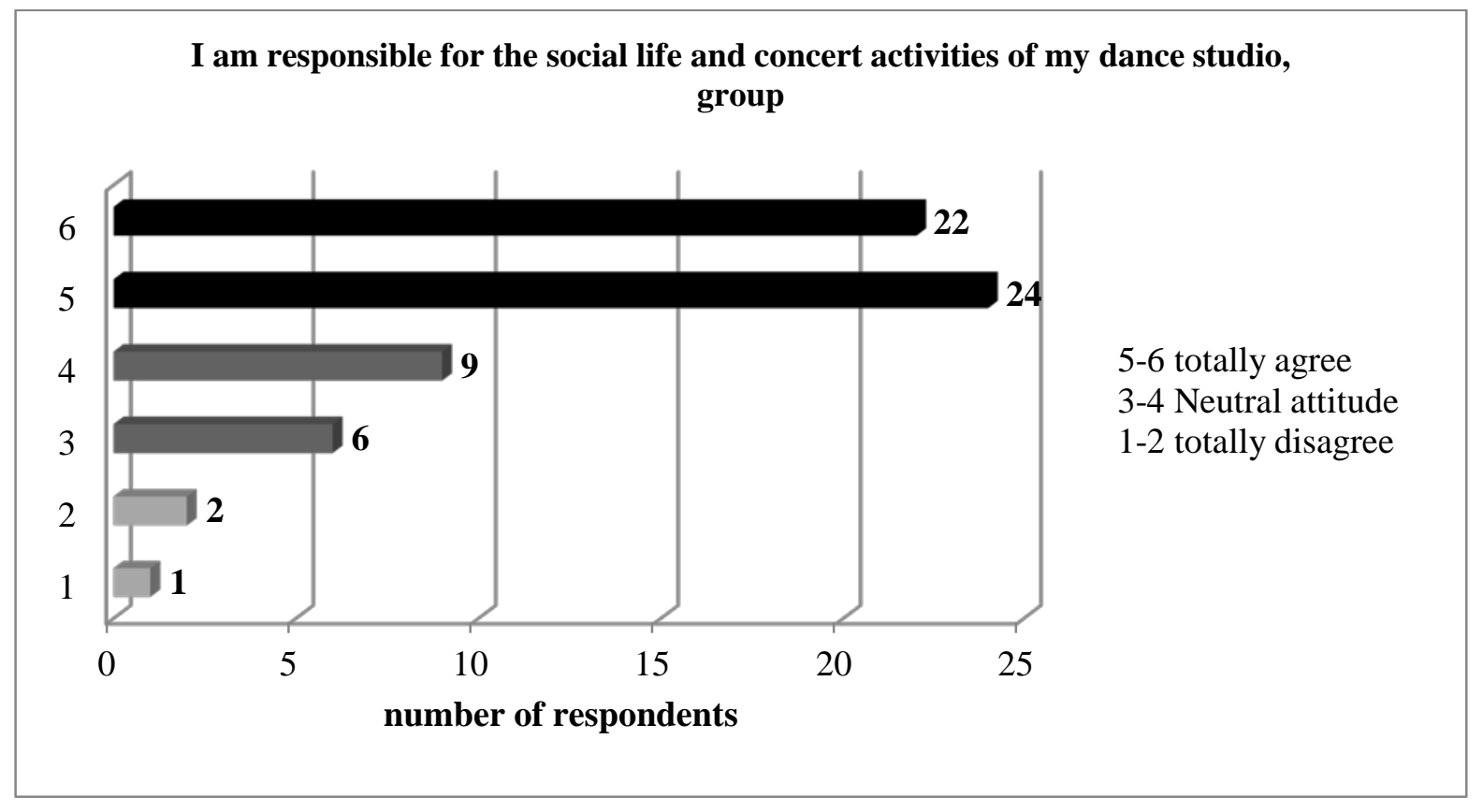

Figure 1 Responsibility for the social life and concert activities of a dance studio, group 
Figure 1 shows the response to attitude towards social life and concert activities of a dance studio or a group. $71.9 \%$ feel responsible and always take care of their dance studio. $23.4 \%$ have a neutral attitude. 3 respondents only occasionally or not at all feel responsible for the social and concert activities of their dance group/studio. The fact that most of the students agree to this statement represents the necessity and significance of the "managers" duties in this profession.

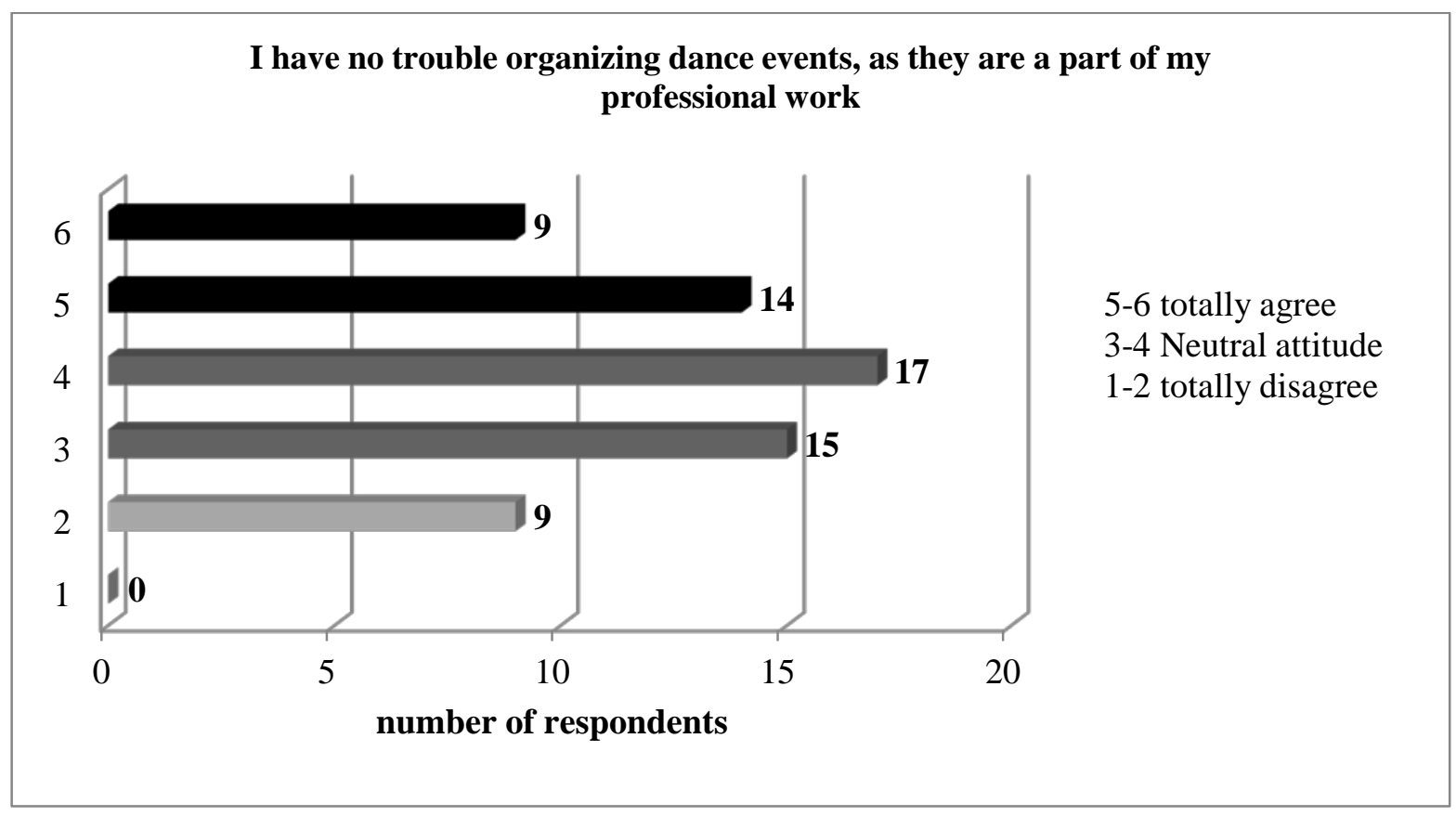

Figure 2 Dance event organization

$35.9 \%$ of respondents admit that they have no difficulty in organizing events and consider it to be a part of their professional work, but only $14 \%$ mark point 6 and are fully convinced of it. $40.4 \%$ doubt that these duties are a part of their professional activity and yet they do organize events for their dancers. $14 \%$ of respondents admit that they organize events only for the sake of necessity, it is difficult and they do not consider it to be their job.

As the students feel responsible for the social life of their studio, this statement provides information about the real action to prove this responsibility. Students have some trouble in organizing dance events. It could be a lack of knowledge, a lack of experience or disbelieve that it is the duty of a dance teacher to organize such events. 


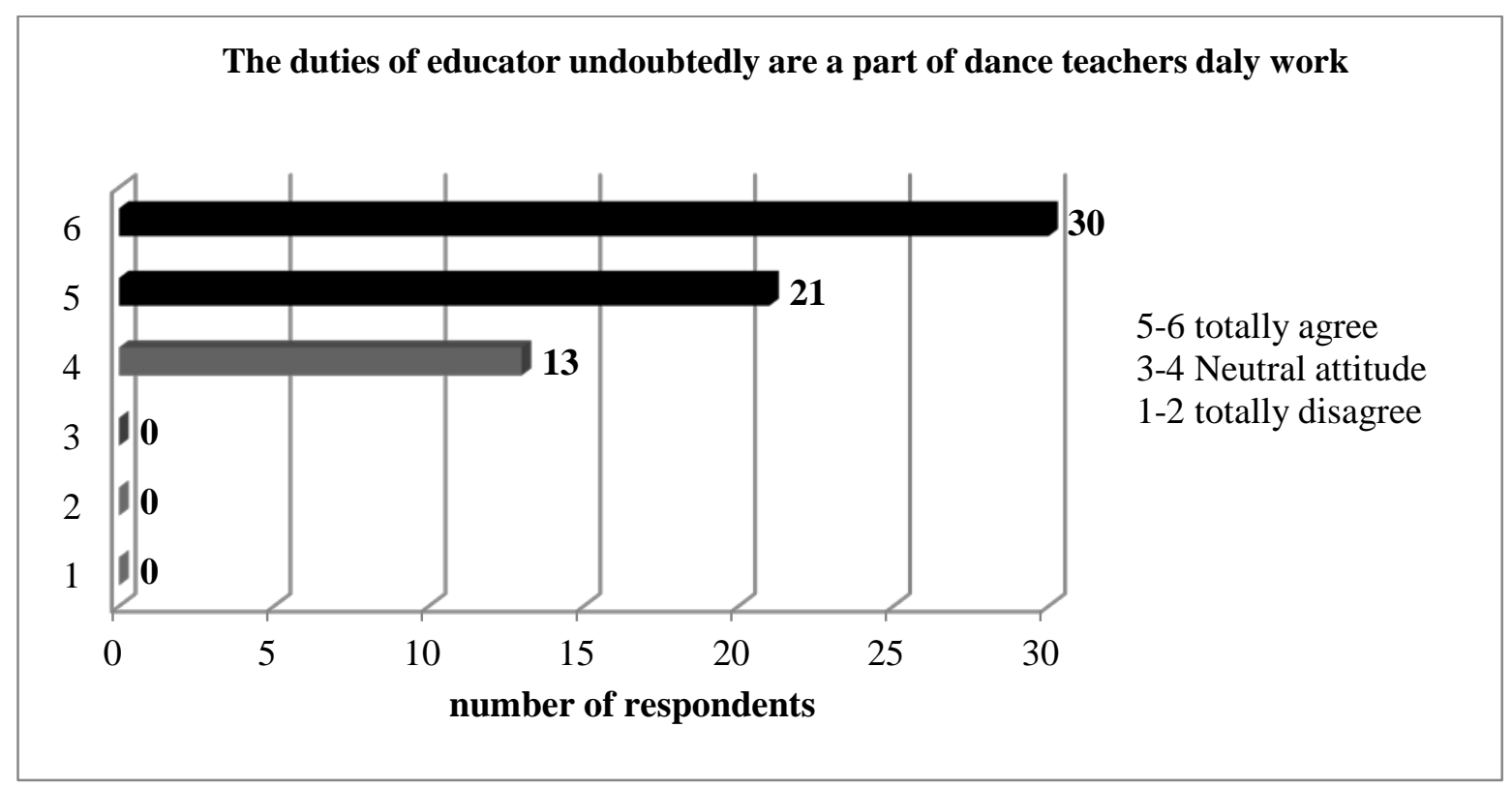

Figure 3 Duties of educator in the profession of a dance teacher

Figure 34 shows respondents' attitude towards the role of educator in dance classes. $79.7 \%$ of respondents do not question the fact that the duties of a teachereducator are constantly present in the daily work of a dance teacher, and only $20.3 \%$ somewhat question this statement and nevertheless admit that they fulfil this role.

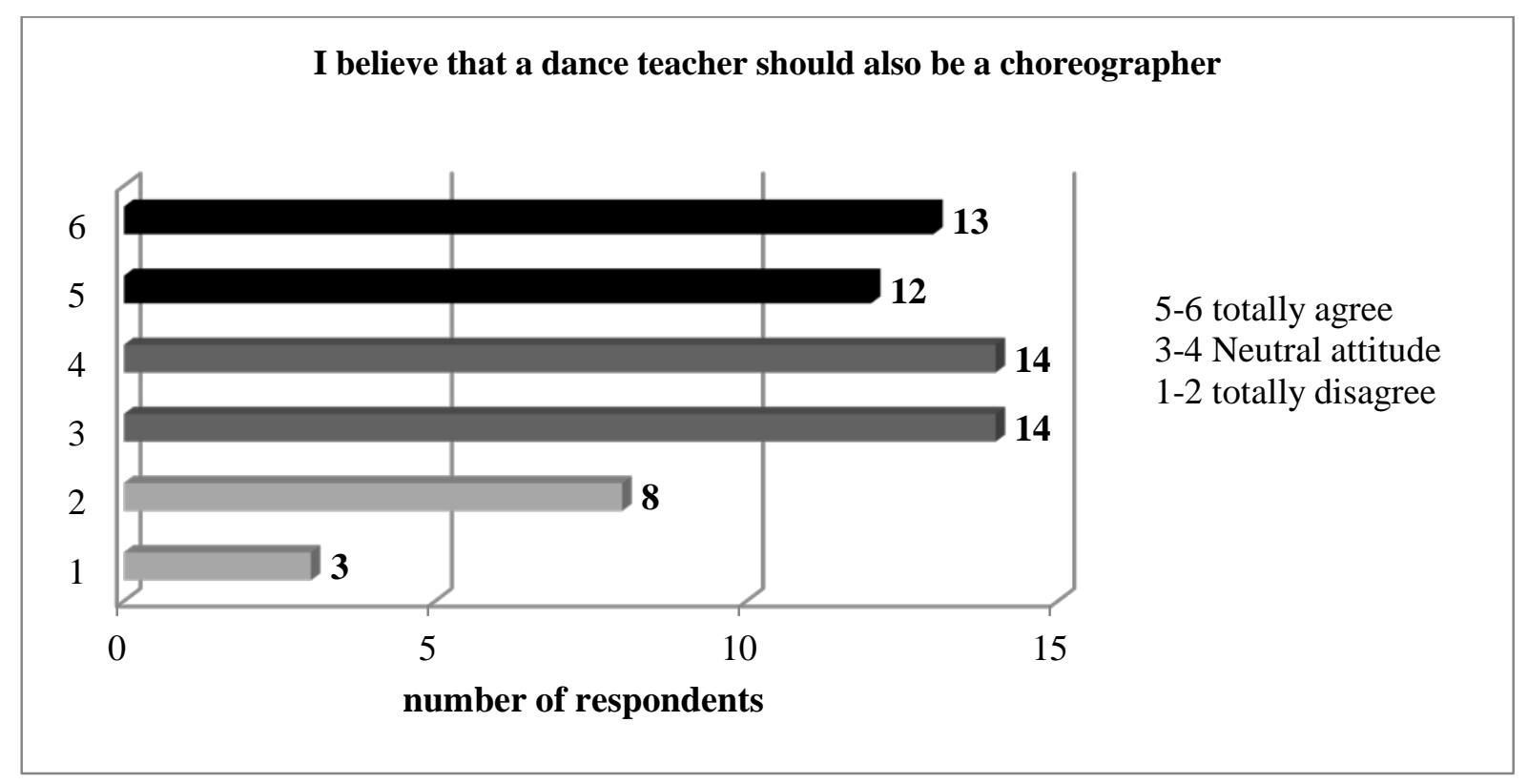

Figure 4 Dance teacher as a choreographer 
The role of educator is important to the majority of students. This fact illustrates understanding of interaction between dancers (children, youth) and a teacher. The role of educator is essential in working with children or youth, and it is as important that the teacher realizes it no matter what is written in his diploma (teacher, choreographer, dancer).

$39 \%$ of respondents believe that a dance teacher should also be a choreographer. $43.8 \%$ have doubts that a dance teacher should also fulfil the role of a choreographer and $17.2 \%$ do not believe that a dance teacher should be a choreographer as well.

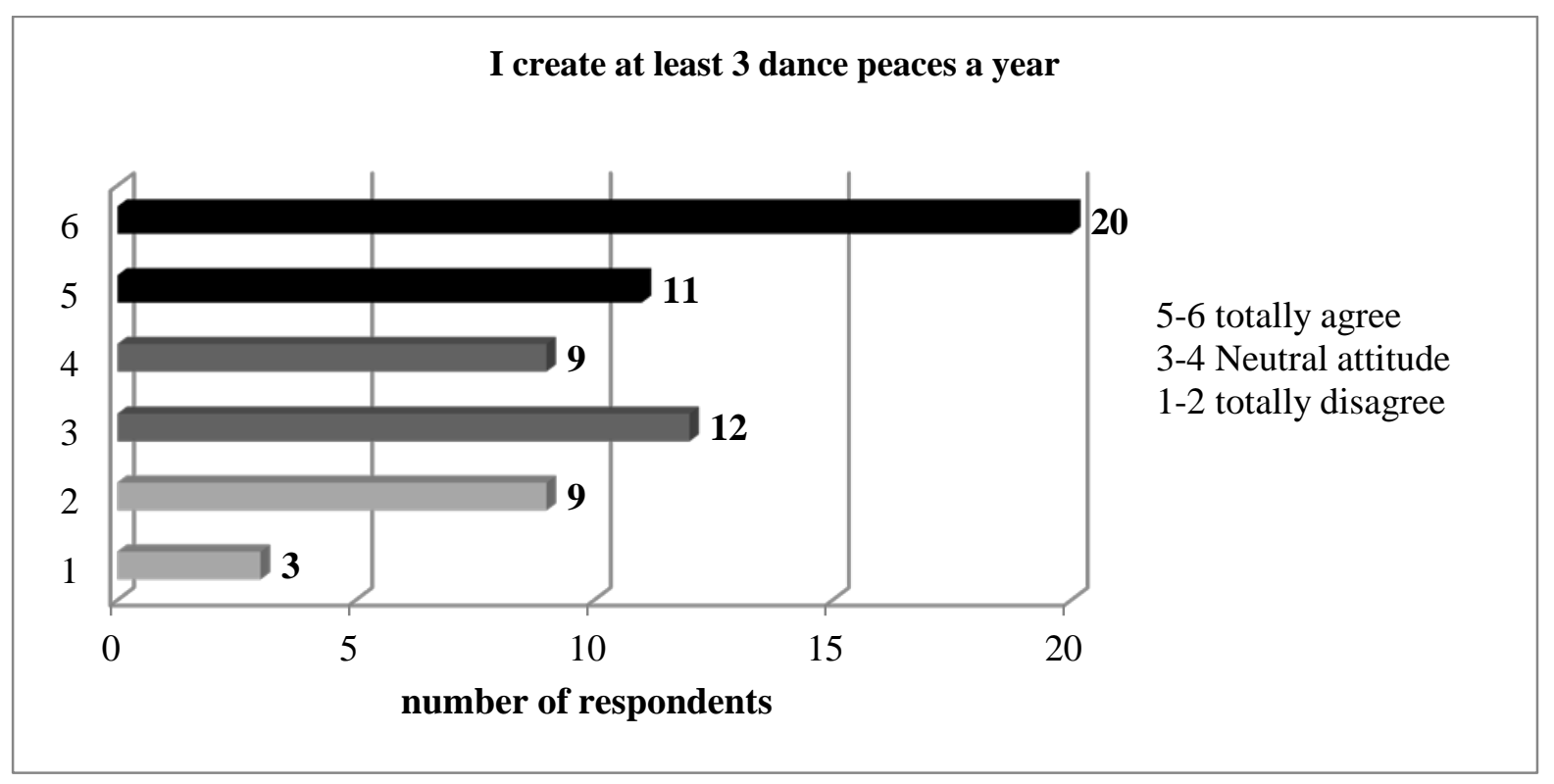

Figure 5 Creation of dances per year

In the statement about the numerical significance of dance production$48.4 \%$ of the respondents create at least 3 new dance compositions per year. $32.8 \%$ make 2 dance compositions per year and $18.8 \%$ of the respondents make one dance composition per year or do not create dance pieces at all.

Looking at the statement nr.4 and 5 - 39\% of students believe that a dance teacher should also be a choreographer, but $48.4 \%$ create at least 3 dance compositions per year. That means that some students are forces to create dances and are not fully convinced that it is their professional duty. Nevertheless in a profession of a dance teacher it is very hard to be successful without the knowledge to use skills in choreography/dance composition. Students need to understand it in order to openly receive offered knowledge. 


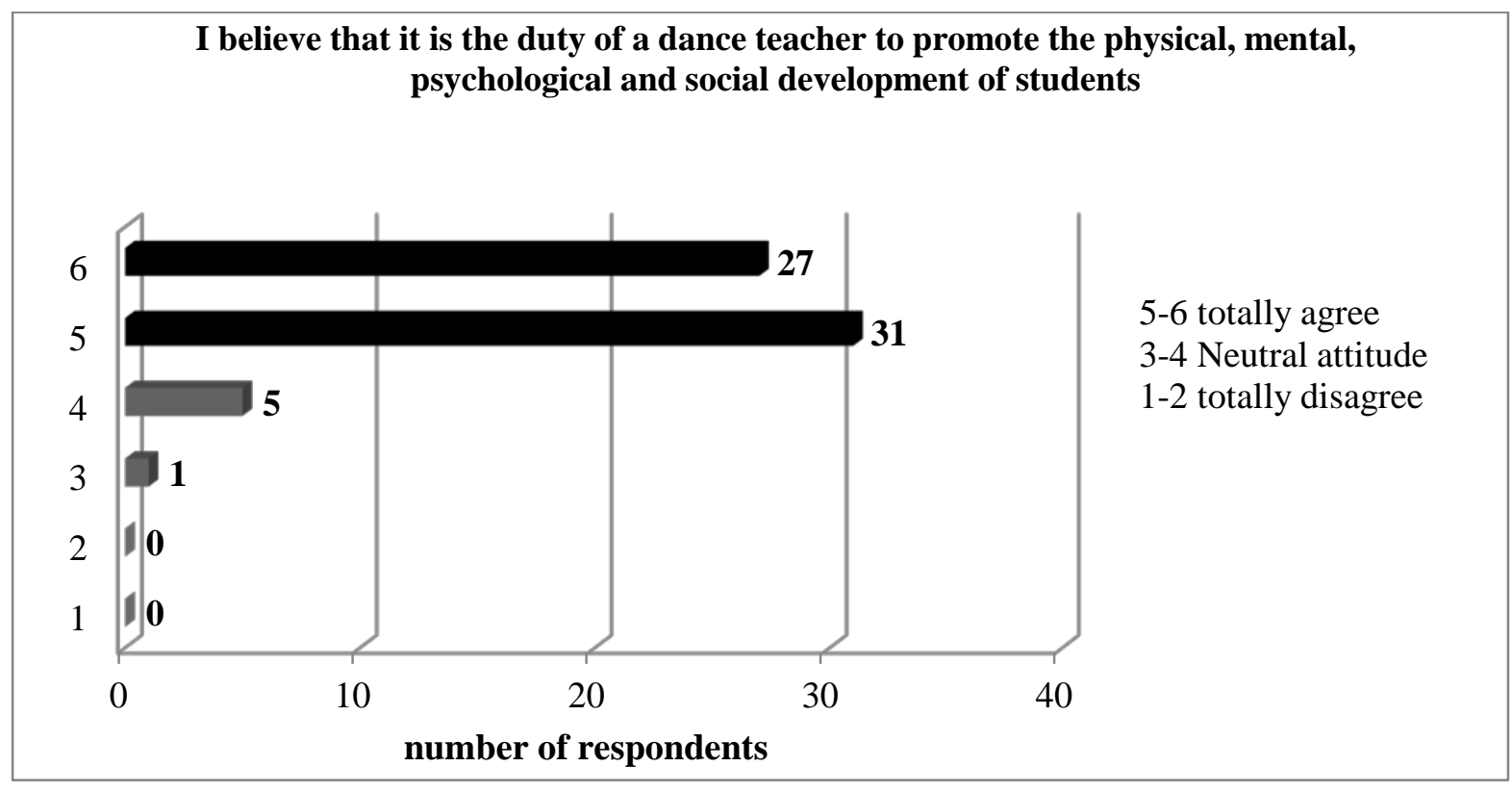

Figure 6 Promotion of physical, mental, psychological and social development of students

Overall, $90.6 \%$ of respondents agree with this statement, of which $42.2 \%$ are fully convinced marking 6 points and $48.4 \%$ mark 5 points. 9.4\% are unconvinced or believe that they only contribute a part of the physical, mental, psychological and social development of students.

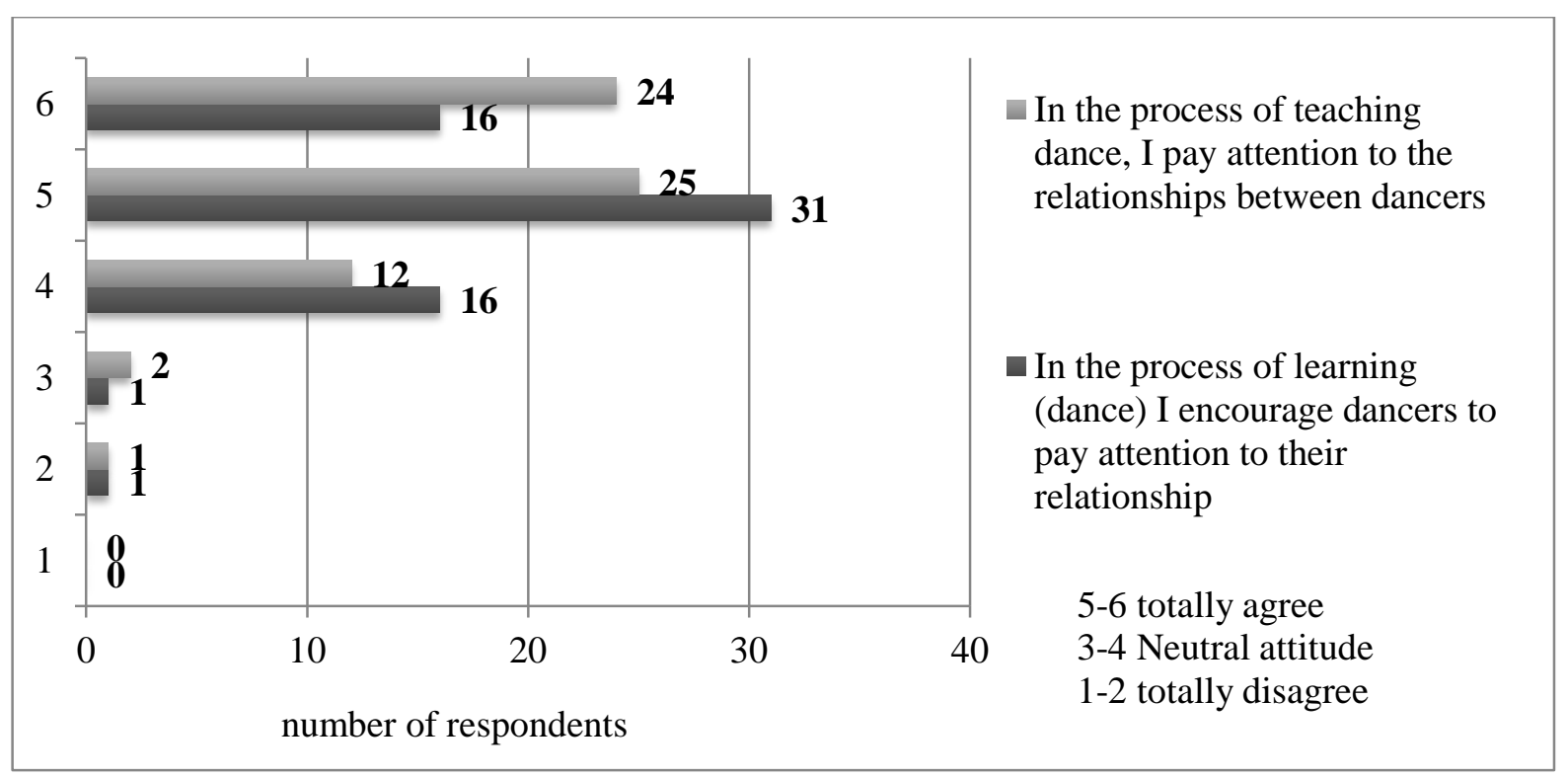

Figure 7 Relationships between the dancers in a process of learning

Looking at Figure 7, it can be seen that $76.6 \%$ of the respondents as teachers pay attention to the dancers' relationship and $73.4 \%$ encourage the dancers themselves to pay attention to their relationship. $21.9 \%$ predominantly but not 
always pay attention to the dancers' relationship and 26.6\% do not always encourage the dancers to do it. In contrast 1 respondent disagrees with these statements.

It is essential to pay attention to the relationships that are occurring between dancers and to promote the awareness of this interaction. These relationships can promote the artistically creative development of personality and successful realization of dance choreography/ production.

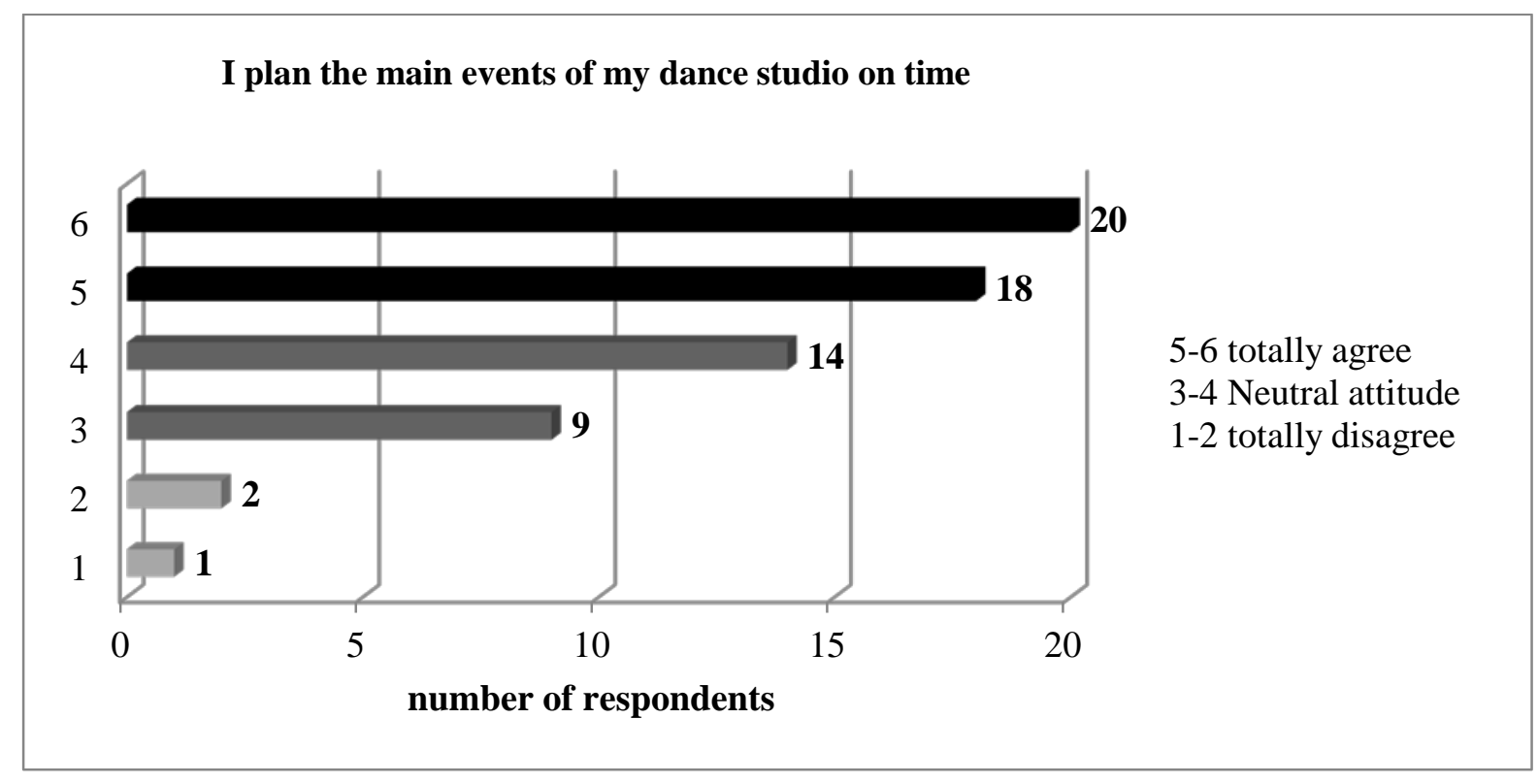

Figure 8 Event planning

$59.4 \%$ of the respondents state they plan their main events in a timely manner and $35.9 \%$ not always plan the events in advance, and 3 respondents don't pay attention to planning or do it only occasionally.

This statement illustrate the managing side of a dance teacher's profession and during the time of studies and practise aspiring dance teachers need to recognize their professional duties and function so that there will be no doubts or misunderstandings. 


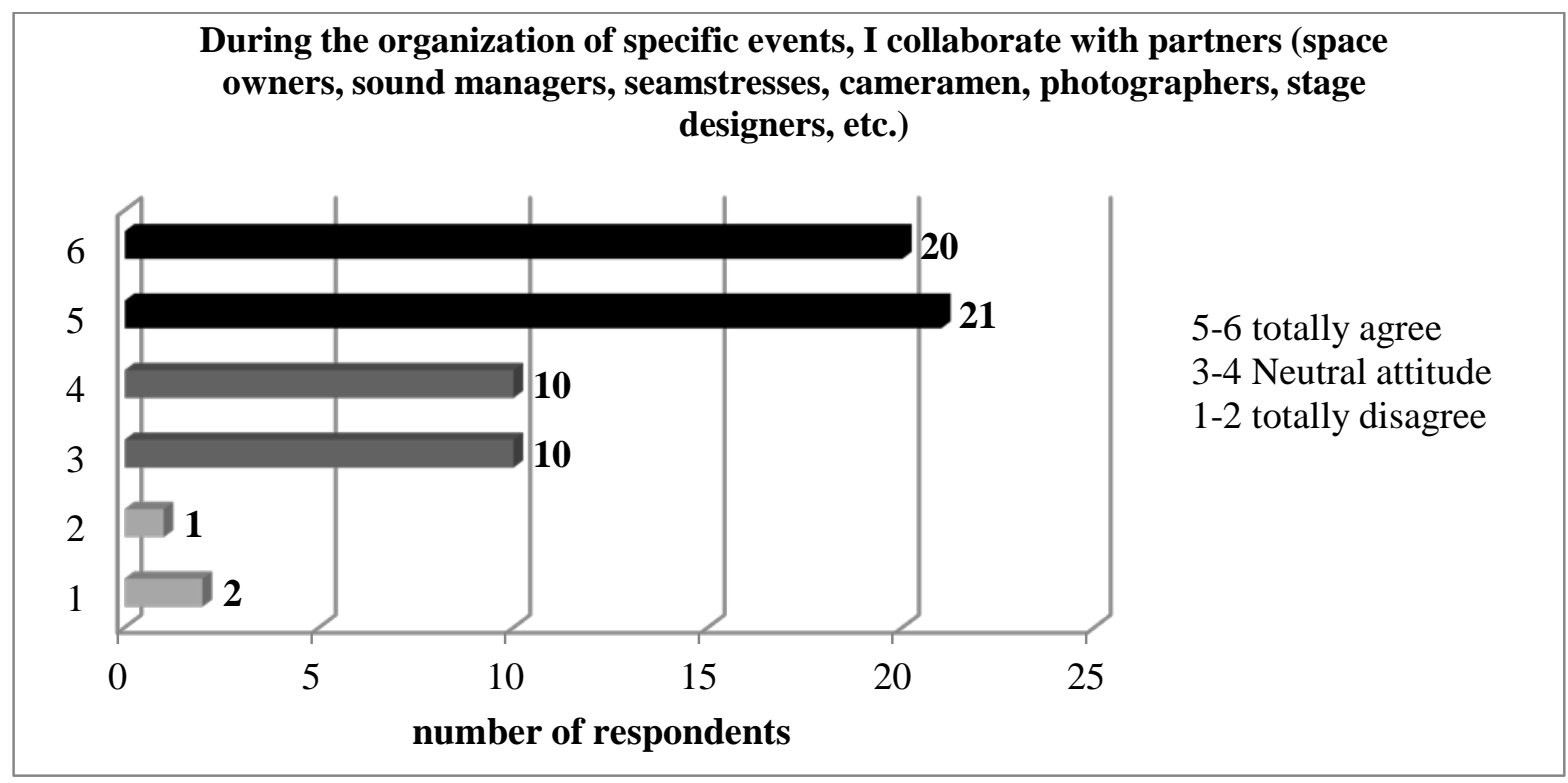

Figure 9 Collaboration with partners

64.1\% admit that they cooperate with specialists from different fields during the organization of events. $31.3 \%$ of respondents state that most of the time they submit to this cooperation and 3 respondents strongly disagree with this statement.

In the process of analysing results the additional information about the respondents was taken in to consideration, like: age, work experience, represented dance genre, ongoing and additional education, work load, age of dancer that they are working with, work in private or government sector.

\section{Conclusions and recommendations}

- Students are aware of the need to realize a role of "manager", but they have a lack of knowledge and experience about event organization, event planning and communication with partners;

- Majority of students agree that a dance teacher takes the role of "educator";

- There are a majority of students that agree or feel neutral about the role of "choreographer" in the profession of a dance teacher, nevertheless all of the students create at least 1 dance per year;

- There is a need for a clear point of view about the duties of a dance teacher - what duties are included in this profession and what activities are an individual choice of each teacher.

The author of this article recommends:

- Integrate pedagogy in the process of dance teaching by creating theoretical basis in "Dance pedagogy". Therefore avoid the situations when students in higher education dance progams question the 
necessity of pedagogical theories or avoid the need for students to interpret the content of pedagogical classes;

- As the role of choreographer is one of the main roles in the work of a dance teacher - it is recommended that the process of creating choreographies in the higher education can gain more spiritual/mental approach and not only technically informative one. The subject of dance composition need to provide both - technical and mental comprehension;

- To include the management studies in the study process of higher education, by creating practice in event organization, concert activity planning, developing communication skills and broaden the knowledge in leading a group/studio/school;

- Create a study course dedicated to professional roles of a dance teacher - broaden the understanding and deepen the insight in the profession and all the different possibilities that can occur in the daily work of a dance teacher.

\section{References}

Anspaks, J. (2006). Mākslas pedagogija 2. Rīga: Raka.

Celma, D. (2006) Vadītājs un vadīšana izglìtībāa. Rīga: RaKa.

Everard, K.B., Morris, G., Wilson, I., \& Chapman P. (2004). Effective school management. 4th edition. SAGE Publications Ltd., USA, California.

N̦ikiforovs, O. (2007). Psihologija pedagogam. Rīga: Izglītības soḷi.

S̆́pona, A. (2006). Audzināšanas process teorijā un praksē. Rīga: Raka. 